
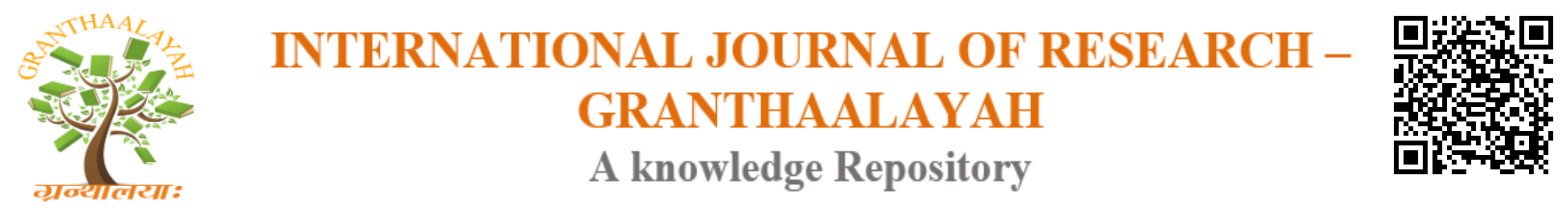

Science

\title{
THREE POINT RESECTION IN 3D WITH DISTANCES
}

\author{
Bektas,S. ${ }^{1}$, Karaahmetoğlu,N. ${ }^{1}$, Yıldırm,R. ${ }^{1}$, Uyar,A. ${ }^{1}$, Yıldırım,Ü,K. ${ }^{1}$, Pakel,E. *1 \\ ${ }^{1}$ Geomatics Engineering, Faculty of Engineering, Ondokuz Mayis University, Samsun, 55139, \\ Turkey
}

\begin{abstract}
In this study, we will consider Three Point Resection in 3D with Distances. This problem is also called Space Resection. The problem of determining the position continues to be the most important problem of geodesy. With the development of measuring instruments and techniques, the widespread use of electronic distance meters, the precise and rapid computation possibilities provided by artificial ground satellites and computers, the segmented approach in the positioning problem (separate calculation of horizontal and vertical coordinates) has left the place as an integrated approach, three dimensional coordinates have begun to be calculated together. The problem of position determination is done either in the form of basic homework or (usually) predictions. It is also possible to calculate the three-dimensional coordinates of the points by the proposed resection method.
\end{abstract}

Keywords: Resection in 3D; Three Dimensional Positioning; Positioning Determination with Length; Least Squares Method.

Cite This Article: Pakel E., Bektas S., Karaahmetoğlu N., Yıldırm R., Uyar A., and Yıldırım Ü K.. (2018). "THREE POINT RESECTION IN 3D WITH DISTANCES." International Journal of Research - Granthaalayah, 6(2), 292-298. https://doi.org/10.5281/zenodo.1194735.

\section{Introduction}

The problem of geodesic positioning problem was resolved separately as horizontal positioning and vertical positioning.

However, due to the widespread use of electronic distance meters, artificial ground satellites, and accurate and fast computation possibilities provided by computers, the piecewise approach of locating (leaving horizontal and vertical coordinates separately) has left the place as an integrated approach and the three-dimensional coordinates of the points have begun to be calculated together.

Proposed method is iterative based. There are a few studies on closed solutions in the literature [17],[18],[19]. However, the formulas proposed as closed solutions are very long and complicated and are considered to provide no practical benefit. 


\subsection{Three Point Resection in 2D with Distances $(y, x)$}

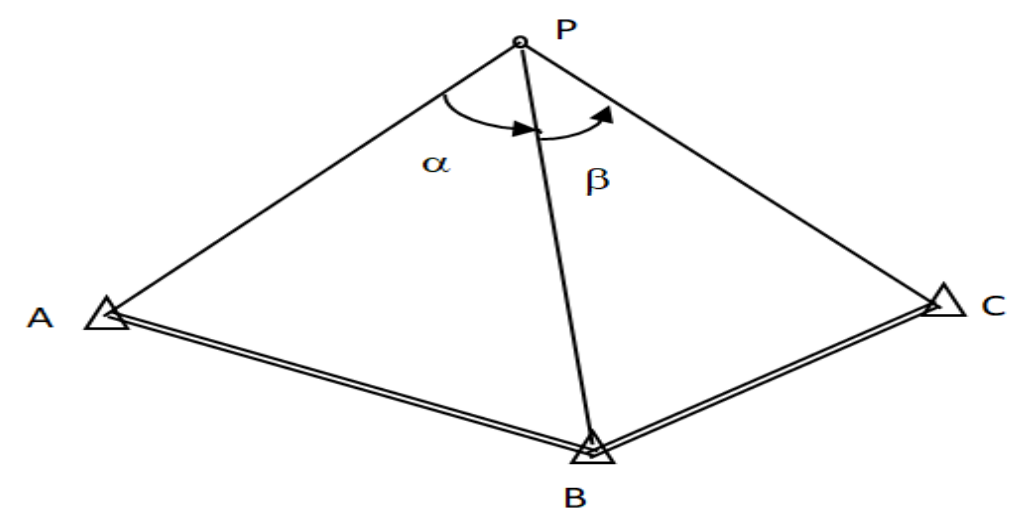

Figure 1: Three point resection in the plane [6]

The three-point resection problem in surveying involves occupying an unknown point and observing angles only to three known points. Today, with the advent of total stations/EDMs, the problem is greatly simplified. If the unknown point $\mathrm{P}$ lies on a circle defined by the three known control points then the solution is indeterminate or not uniquely possible. There are, theoretically, an infinite number of solutions for the observed angles. This situation is called dangerous circle. If the geometry is close to this, then the solution is weak. In addition, there is no solution to this problem when all the points lie on a straight or nearly straight line. There are a number of approaches to solving the resection problem. The coordinates of points $\mathrm{A}, \mathrm{B}$, and $\mathrm{C}$ are known and the angles $\alpha$ and $\beta$ measured at point P. [17], [6]

Kaestner-Burkhardt Method, in the Kaestner-Burkhardt approach [7], [8], [10], [16] the coordinates of points $\mathrm{A}, \mathrm{B}$, and $\mathrm{C}$ are known and the angles $\alpha$ and $\beta$ measured at point $\mathrm{P}$. Collins Method, The Collins (or Bessel's) method [7], [8], [10], [16] is different in that the problem is broken down into two intersections. Cassinı Method, The Cassini approach [7], [10], [16] to the solution of the three-point resection problem is a geometric approach. Tienstra Method, The Tienstra method [3] is also referred to as the Barycentric method. An easy to understand proof is given in [1].

Among these methods, resection methods provide a great measure in the field compared to others. The rewind method is advantageous compared to other shortcut methods, since it is only necessary to make measurements at the point to be estimated. It is easier to make the resection with the horizontal direction measure than with the resection with the length measure [5]. Because, in order to measure the lengths, one person must go to at least two points and hold reflector. It is possible to calculate the coordinates of the point $\mathrm{P}$ with three horizontal directions (two angles) to be made to three points whose coordinates are known only via a $\mathrm{P}$ point for which the calculation of the coordinates is desired. In other shortcut methods there is a necessity to measure at least two points. There is no solution if the dangerous circle dropping point, which is to be estimated in the method of rewinding with the correct measure, i.e. the point to be cut and the other three fixed points are located on the same circle. Theoretically, it is very unlikely to happen in practice. We look at measuring information and geodetic calculus books for reworking accounts and methods. 
There is a danger that the resolution cannot be done in the resection method. If the point to be estimated and the other three fixed points are on the same circle, there is no solution. Theoretically, the probability of occurrence of this condition is extremely small. For detail information please look at measurement methods and geodetic calculations books.

\subsection{Three-Dimensional Positioning $(y, x, z)$}

It is possible to calculate the three-dimensional local orthogonal coordinates of the points by the re-truncation method. It is possible to solve this problem by taking advantage of the measured slope lengths. In this case, the problem is also referred to as space re-traction.

In this method, the three-dimensional coordinates are to be calculated between a point $\mathrm{P}$ and at least three points such as $\mathrm{A}\left(y_{a}, x_{a}, z_{a}\right), \mathrm{B}\left(y_{b}, x_{b}, z_{b}\right)$ ve $\mathrm{C}\left(y_{c}, x_{c}, z_{c}\right)$ The $3 \mathrm{D}$ coordinates of the $\mathrm{P}$ $\left(y_{p}, x_{p}, z_{p}\right)$ point can be calculated by the $d_{a}, d_{b}, d_{c}$ slope distance measure. Geometric solution of the problem is the intersection of 3 spheres is found which are a center and $d_{a}$ radius, B center $d_{b}$ radius and $\mathrm{C}$ center $d c$ radius. [5]

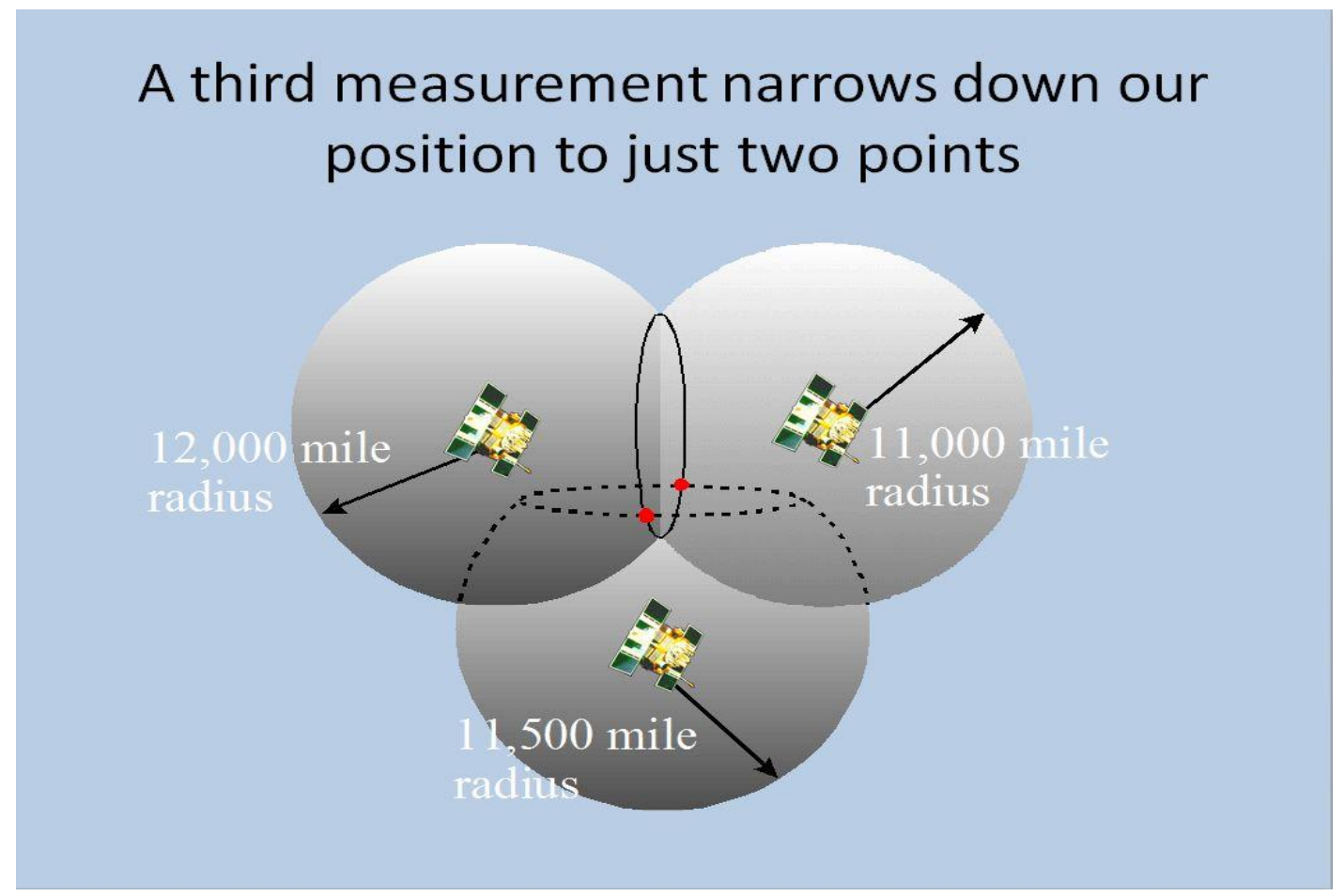

Figure 2: Intersection of three sphere [18]

The intersection of the three spheres gives us 2 points. Because, the intersection of two spheres gives us a circle. The intersection of the third sphere and this intersection circle 2 points. There are two solutions [18].

The approximate coordinate chosen for the point to be estimated will be determines the one of two solution. It is important to select approximate coordinates. If the approximate coordinates are not determined in proper proximity, the iterative solution yields the possibility of nonconvergence. 
The positioning of GPS receivers is also based on this. For the solution of the problem, the slope length equation between the following two points written for each measure.

$$
d_{i}=\sqrt{\left(x_{i}-x_{p}\right)^{2}+\left(y_{i}-y_{p}\right)^{2}+\left(z_{i}-z_{p}\right)^{2}} \quad(i=a, b, c)
$$

The three unknowns of these three equations cannot be solved easily because the equations are not linear. For this, the approximate values $y_{o}, x_{o}, z_{o}$ of the unknowns (coordinates of the point P) are selected.

$$
y_{p}=y_{o}+\Delta_{y} \quad x_{p}=x_{o}+\Delta_{x} \quad z_{\mathrm{p}}=z_{o}+\Delta_{z}
$$

And the equations are opened to the Taylor series and if the linearization is done only by the first degree terms, the following linear equation system is obtained. The selection of the approximate values of the coordinates of the point to be estimated can be read out on a large scale map or can be determined roughly from the coordinates of other fixed points. Where $\mathrm{x}, \mathrm{y}, \mathrm{z}$ denote $\mathrm{x}, \mathrm{y}$ the horizontal position and $\mathrm{z}$ coordinates is the vertical.

The system of linearized equations,

$$
\left.\left.\begin{array}{rrr}
\left(x_{a}-x_{0}\right) / d_{a} & \left(y_{a}-y_{0}\right) / d_{a} & \left(z_{a}-z_{0}\right) / d_{a} \\
\left(x_{b}-x_{0}\right) / d_{b} & \left(y_{b}-y_{0}\right) / d_{b} & \left(z_{b}-z_{0}\right) / d_{b} \\
\left(x_{c}-x_{0}\right) / d_{c} & \left(y_{c}-y_{0}\right) / d_{c} & \left(z_{c}-z_{0}\right) / d_{c}
\end{array}\right] \quad\left[\begin{array}{c}
\Delta x \\
\Delta y \\
\Delta z
\end{array}\right]=\underset{\mathrm{x}}{\mathrm{A}}=\begin{array}{c}
d_{0 a}-d_{a} \\
d_{0 b}-d_{b} \\
d_{0 c}-d_{c}
\end{array}\right]
$$

Can be written

$\mathrm{Ax}=b$

Solution of this linear equation system by any method

$x=A^{-1} b$

or MATLAB command

$$
x=\operatorname{inv}(A) * b \quad \text { or } \quad x=A \backslash b
$$

$\Delta \mathrm{x}, \Delta \mathrm{y}, \Delta \mathrm{z}$ unknowns are added and added to the initially selected approximate values

$y_{p}=y_{o}+\Delta_{y} \quad x_{p}=x_{o}+\Delta_{x} \quad z_{\mathrm{p}}=z_{o}+\Delta_{z}$

the coordinates of the desired $\mathrm{P}$ point are found. When the linearization process is performed, the selected approximate values are not as close to real values as they are, and the exact result cannot be reached because of the influence of the second and higher order terms ignored. For this, the values found in the first step 
$y_{o}=y_{p} \quad x_{o}=x_{p} \quad z_{o}=z_{p}$

The equation is re-established and solved.

But here the $z_{p}$ calculated value of the point $\mathrm{P}$ will be the height of the optical axis of the theodolite at point $\mathrm{P}$. The height of the instruments (a) must be subtracted from the $z_{p}$ calculated value for the true $z_{p}$.

Three slope edge measures are sufficient to allow the algebraic solution to be performed without space space resection. More than three measures can be used to further increase the accuracy, as well as vertical angle measurements and slope length measurements. In this case, since the number of equations is greater than the number of equations in the linear equations established as $A x=b$ as above, the system of equations according to Least Squares Principle;

$$
A^{T} A x=A^{T} b
$$

Is converted and

$x=\left(A^{T} A\right)^{-1} A^{T} b$

$\Delta \mathrm{x}, \Delta \mathrm{y}$ and $\Delta \mathrm{z}$ are found in a balanced way. The space to be made with lengths will be the value of the jaw axis of the tool, if it is found to be reduced to the gauge floor without space resection. For this reason, the tool height must be subtracted separately from the calculated $\mathrm{Z}$ value.

\subsection{Difficulties in practice}

Especially in the case of algebraic solutions where only 3 length measures are encountered, $A$ matrix may has bad conditions. In such problems, iterative solutions cannot converge and the result cannot be reached. We recommend using the MATLAB pinv command to take advantage of the pseudo inverse. Instead of equation (6) use below equation

$$
x=\operatorname{pinv}(A, 0.02) * b
$$

The use of more than three length measurements and the selection of fixed points homogeneously distributed on the horizon will eliminate this problem altogether.

\section{Numerical Application}

Calculation of the three-dimensional coordinates of point 500 using the following coordinates of points 100, 101 and 102 and the slope distance measurements.

Table 1: Fixed points coordinates

\begin{tabular}{|cccc|}
\hline Point & Y & X & Z \\
\hline 100 & 371.180 & 437.180 & 140.410 \\
\hline 101 & 325.140 & 212.380 & 140.360 \\
\hline 102 & 116.470 & 348.960 & 140.850 \\
\hline
\end{tabular}


Table 2: Approximate values for unknown point

\begin{tabular}{|cccc|}
\hline Point & Y & $\mathbf{X}$ & $\mathbf{Z}$ \\
\hline 500 & 227.000 & 340.000 & 209.000 \\
\hline
\end{tabular}

Table 3: Slope distances

\begin{tabular}{|cccl|}
\hline $\boldsymbol{i}$ & from & to & slope distance \\
\hline 1 & 100 & 500 & 186.105 \\
\hline 2 & 101 & 500 & 174.752 \\
\hline 3 & 102 & 500 & 132.139 \\
\hline
\end{tabular}

$A$ coefficient matrix

$\begin{array}{rrr}0.5199 & 0.7714 & -0.3670 \\ -0.7292 & 0.5608 & -0.3922 \\ 0.0688 & -0.8492 & -0.5236\end{array}$

$b$ right hand side vector

$b^{T}=\left[\begin{array}{lll}0.8078 & 0.2616 & -1.9792\end{array}\right]$

Table 4: Iteratively calculated coordinates of unknown point 500

\begin{tabular}{|ccccccc|}
\hline & $\mathbf{d y}$ & $\mathbf{d x}$ & $\mathbf{d z}$ & $\mathbf{Y = Y o + d y}$ & $\mathbf{X = X o + d x}$ & $\mathbf{Z = Z o + d z}$ \\
\hline Iteration & $\mathbf{( \mathbf { c m } )}$ & $\mathbf{( c m )}$ & $\mathbf{( c m )}$ & $\mathbf{( m )}$ & $\mathbf{( m )}$ & $\mathbf{( m )}$ \\
\hline 1 & 155.47 & 14.93 & 127.81 & 228.5547 & 340.1493 & 210.2781 \\
\hline 2 & 0.74 & -0.28 & -1.34 & 228.5620 & 340.1465 & 210.2648 \\
\hline 3 & -0.00 & 0.00 & -0.00 & 228.5620 & 340.1465 & 210.2648 \\
\hline
\end{tabular}

\section{Conclusion}

Figure 3: Demonstration of intersection of three sphere

It is possible to easily calculate the three-dimensional coordinates of the terrain points by taking advantage of the length to be made to at least three points whose coordinates are known to the working region. Certainly, it is not appropriate to expect high accuracy from the method. In this way, the method can be used in engineering works that do not require high accuracy (mining measurements, geological, geophysical, navigation, forestry, construction, etc.). The advantage of the method is that it can only determine the three-dimensional position using three measures. It is possible to balance high accuracy, quality and over-all of the measurements in excess. For this; (horizontal direction, vertical angle, slope distance, geometric level and even GPS 
measurement values) and number can be increased in addition to increasing the quality of the measurement by making all necessary reductions in the measurements.

\section{References}

[1] Allan, A., Hollwey, J., and Maynes, J., 1968. Practical Field Surveying and Computations, American Elsevier Publishing Co., Inc., New York.

[2] Anderson, J. and Mikhail, E., 1998. Surveying: Theory and Practice, 7th edtion, WCB/McGrawHill, New York.

[3] Bannister, A., Raymond, S., and Baker, R., 1984. Surveying, 6th edition, Longman Scientific \& Technical, Essex, England.

[4] Bektaş, S (1992)."Nirengi Ağlarının Üçboyutlu Dengelenmesi ", Türkiye III. Harita ve Teknikerlik Hizmetleri Kurultayı ", 13-16 Nisan 1992 Ankara

[5] Bektaş,S. (1997). Uzay Geriden Kestirme, Harita ve Kadastro Mühendisliği Dergisi, say1 : 83 , s.72-79, Ekim 1997, Ankara

[6] Bektaş,S. (2016). Pratik Jeodezi, II.Baskı, OMÜ yayınları, Samsun

[7] Blachut, T., Chrzanowski, A., and Saastamoinen, J., 1979. Urban Surveying and Mapping, Springer-Vrlag, New York.

[8] Faig, W., 1972. "Advanced Surveying I (Preliminary Copy), Department of Surveying Engineering Lecture Notes No. 26, University of New Brunswick, Fredericton, N.B., Canada, 225 p.

[9] Hodgson, C., 1957. Manual of Second and Third Order Triangulation and Traverse, USC\&GS Special Publication No. 145 (Reprinted, 1957), U.S. Government Printing Office, Washington, D.C.

[10] Kissam, P., 1981. Surveying for Civil Engineers, 2nd edition, McGraw-Hill, New York.

[11] Klinkenberg, H., 1955. "Coordinate Systems and the Three Point Problem", the Canadian Surveyor, XII (8):508-518. SURE 215 -

[12] Surveying Calculations Three Point Resection Problem Page 201 Reynolds, W., 1934.

[13] Manual of Triangulation Computation and Adjustment, USC\&GS Special Publication No. 138 (Reprinted, 1955), U.S. Government Printing Office, Washington, D.C.

[14] Öztürk. E. - Şerbetçi. M.(1989): "Dengeleme Hesabı Cilt II", KTÜ yayınları, yayın no:144, sayfa :310, Trabzon

[15] Şerbetçi, M. -Atasoy, V(1990) :"Jeodezik Hesap", KTÜ yayınları, yayın no: 153, Trabzon

[16] Ziemann, H., 1974. "Terrestrial Surveying Methods", Proceedings of ACSM Fall Convention, Washington, D.C., September, pp 222-233.

[17] Zeng,Z, Wang,X. 1992, A General Solution of a Closed-Form Space Resection, PHOTOGRAMMETRIC ENGINEERING \& REMOTE SENSING, Vol. 58, No.3, March 1992, pp 327-338.

[18] Rampal, K.1979, Closed Solution for Space Resection, PHOTOGRAMMETRIC ENGINEERING AND REMOTE SENSING, Vol. 45, No. 9, September 1979, pp. 1255-1261.

[19] Awange,J.L, Grafarend/Fukuda 2003, Closed form solution of the triple three-dimensional intersection problem, geodaesie.info/.../zfv_2003_6_

[20] URL-1: Three Point Resection Problem, Surveying Engineering Department Ferris State University, Accessed date .27.01.2017

[21] URL-2: http://oarnorthwest.com/wp-content/uploads/2013/02/gps3.jpg, Accessed date: 27.01.2018

*Corresponding author.

E-mail address: erdipakel@ gmail.com 